\title{
First results of experiments with chinese pigs in France 3. Growth and carcass quality in two-way and three-way crosses
}

\author{
C. LEGAULT *, J.C. CARITEZ **, J. GRUAND***, P. SELLIER * \\ *I.N.R.A., Station de Génétique quantitative et appliquée, \\ F 78350 Jouy-en-Josas \\ *: I.N.R.A., Domaine expérimental du Magneraud, \\ Saint-Pierre-d'A milly, F 17700 Surgères \\ **:* I.N.R.A., Station cxpérimentale de Sélection porcine, \\ F 86480 Rouille
}

The offspring of one boar and two sows of each of three Chinese breeds - Meishan (MS), Jiaxing (JX) and Jinhua (JH) - were compared for growth and backfat thickness. Measured on 321 piglets (166 MS, $90 \mathrm{JX}$ and $65 \mathrm{JH}$ ) average birth weight was 880, 840 and $640 \mathrm{~g}$, respectively. Performance testing of 79 gilts (36 MS, $24 \mathrm{JX}$ and $19 \mathrm{JH}$ ) confirmed the differences observed at birth : at mean ages of 157,160 and 150 days, live weight averaged 69,60 and $46 \mathrm{~kg}$, and backfat thickness $31.5,27.5$ and $27.7 \mathrm{~mm}$ respectively for the tirree biceds.

The three Chinese boars were mated at random to 10 Large White $(\mathrm{LW})$ and 12 French Landrace (FL) sows. Mean birth weight of F1 piglets was relatively high and varied from 1.37 to $1.46 \mathrm{~kg}$ according to genetic type. A performance test was carried out in $114 \mathrm{~F} 1$ gilts of which 38,40 and 36 were daughters of the MS, JX and JH boars respectively. At the ages of 136,142 and 136 days, they weighed 84,85 and $76 \mathrm{~kg}$ while mean backfat thickness was $26.3,24.5$ and $27.7 \mathrm{~mm}$, respectively, in the three progeny groups.

These results are in good agreement with those resulting from growth and carcass evaluation of 112 F1 castrated males, brothers of the former gilts. On average, growth was very fast (slaughter weight of $99 \mathrm{~kg}$ at an average age of 159 days) but carcasses were very fat (47 p. 100 of lean cuts versus 21 p. 100 of fat cuts). However, the progeny of the JH boar had a significantly lower growth, a significantly fatter carcass, and a significantly better meat quality than the other two progeny groups, as indicated by better colour and higher water holding capacity. Finally, 17 F1 sows (Half Chinese) and 9 "control » sows $(\mathrm{LW} \times \mathrm{FL})$ were inseminated at random with semen from 4 Belgian Landrace boars. Growth and carcass evaluation was made on 137 pigs (34 1/4 MS, $391 / 4 \mathrm{JX}, 321 / 4 \mathrm{JH}$ and 32 «controls»). As compared to the "controls», 1/4 MS animals were slaughtered 9 days sooner (at $100 \mathrm{~kg}$ live weight) while $1 / 4 \mathrm{JX}$ and $1 / 4 \mathrm{JH}$ respectively were slaughtered 11 and 17 days later. Food conversion ratio was increased in the $1 / 4$ Chinese pigs by 0.13 to 0.37 according to the genetic combination. The best dressing percentage was observed in $1 / 4 \mathrm{JH}(+0.9 \mathrm{p}$. 100), while the poorest one was observed in $1 / 4 \mathrm{MS}(-1.4 \mathrm{p} .100)$. Carcasses of $1 / 4 \mathrm{JH}$ were the shortest and the fattest. The proportion of lean cuts (ham and loin) was $3.5 \mathrm{p} .100$ lower in the $1 / 4$ Chinese pigs whereas the proportion of fat cuts (back and leaf fat) increased from 1.0 p. 100 in $1 / 4$ MS to 3.5 p. 100 in $1 / 4 \mathrm{JH}$.

All meat quality criteria (colour, water holding capacity and $\mathrm{pH}$ ) were improved in the $1 / 4$ Chinese pigs, as compared to "controls»: However, all observed differences were not significant.

The reduction in value per $\mathrm{kg}$ carcass ranged from $0.25 \mathrm{~F} / \mathrm{kg}$ in $1 / 4 \mathrm{MS}$ to $0.30 \mathrm{~F} / \mathrm{kg}$ in $1 / 4 \mathrm{JH}$. If this is combined with the results of fattening performance (especially food conversion), the total "gross margin loss » varied from 45 to $65 \mathrm{~F} / \mathrm{pig}$ in the $1 / 4$ Chinese pigs as compared to "controls». These preliminary results have to be confirmed in order to give an accurate estimation of the advantages of using some Chinese breeds for crossbreeding in our country. This estimation mainly depends on the balance between the gain relative to the decreased cost price of the piglet at weaning, and the loss relative to increased feed cost and decreased sale price of the fattening pig. 